\title{
A One Health Approach to Defining Animal and Human Helminth Exposure Risks in a Tribal Village in Southern India
}

\author{
Alexandra Sack, ${ }^{1}$ Gokila Palanisamy, ${ }^{2}$ Malathi Manuel, ${ }^{2}$ Chinnaduraipandi Paulsamy, ${ }^{2}$ Anuradha Rose, ${ }^{3}$ \\ Saravanakumar Puthupalayam Kaliappan, ${ }^{2}$ Honorine Ward, ${ }^{4}$ Judd L. Walson, ${ }^{5,6}$ Katherine E. Halliday, ${ }^{5,7}$ and \\ Sitara Swarna Rao Ajjampur ${ }^{2 *}$ \\ ${ }^{1}$ Clinical and Translational Science Graduate Program, Tufts University Graduate School of Biomedical Sciences, Boston, Massachusetts; ${ }^{2}$ The \\ Wellcome Trust Research Laboratory, Division of Gastrointestinal Sciences, Christian Medical College, Vellore, Tamil Nadu, India; ${ }^{3}$ Department of \\ Community Medicine, Christian Medical College, Vellore, Tamil Nadu, India; ${ }^{4}$ Division of Geographic Medicine and Infectious Diseases, Tufts \\ Medical Center, Tufts University School of Medicine, Boston, Massachusetts; ${ }^{5}$ Departments of Global Health, Medicine (Infectious Disease), \\ Pediatrics and Epidemiology, University of Washington, Seattle, Washington; ${ }^{6}$ The DeWorm3 Project, University of Washington, Seattle, \\ Washington; ${ }^{7}$ Faculty of Infectious and Tropical Diseases, London School of Hygiene \& Tropical Medicine, London, United Kingdom
}

\begin{abstract}
The high burden of soil-transmitted helminth infections has been studied in India; however, little data exist on zoonotic helminths, and on animal-associated exposure to soil-transmitted helminths. Our study took place in the Jawadhu Hills, which is a tribal region in Tamil Nadu, India. Using a One Health approach, we included animal and environmental samples and human risk factors to answer questions about the associations among infected household soil, domestic animals, and human risk factors. Helminth eggs were identified by microscopy in animal and soil samples, and a survey about risk factors was administered to the head of the household. Contact with animals was reported in $71 \%$ of households. High levels of helminth infections were found across domestic animal species, especially in goats, chickens, and dogs. Helminth eggs were recorded in $44 \%$ of household soil ( $n=43 / 97)$ and separately in $88 \%$ of soil near a water source $(n=28 / 32)$. Animal contact was associated with 4.05 higher odds of having helminth eggs in the household soil $(P=0.01)$, and also having a water source at the household was associated with a 0.33 lower odds of having helminth eggs in the household soil $(P=0.04)$. Soil moisture was a mediator of this association with a significant indirect effect $(P<$ 0.001). The proportion mediated was 0.50 . While our work does not examine transmission, these results support consideration of animal-associated exposure to STH and potentially zoonotic helminths in future interventions to reduce helminth burden. Our study provides support for further investigation of the effects of animals and animal fecal matter on human health.
\end{abstract}

\section{INTRODUCTION}

A recent systematic review estimated that a quarter of the population of South Asia was infected with soil-transmitted helminths (STH). ${ }^{1}$ STH, comprised of Ascaris spp., Trichuris spp., and hookworms (Ancylostoma spp. and Necator spp.), are so-named because of the importance of contaminated soil in their transmission cycle. ${ }^{2}$ These infections are linked to water, sanitation, and hygienic $(\mathrm{WaSH})$ practices, as well as socioeconomic status. ${ }^{3}$ The $\mathrm{WHO}-$ recommended control measure for STH is mass drug administration (MDA) to preschool-aged and school-age children (PSAC and SAC). ${ }^{4}$ In India, the National Deworming Day (NDD), coordinated by the Ministry of Health and Family Welfare, targets children aged 1 to 19 years with biannual MDA through anganwadi centers and schools, and NDD is the largest deworming program in the world. ${ }^{5}$ Despite this highly successful program, which aimed to deworm 240 million children and adolescents in 2019, persistently high levels of STH infections are reported across many areas of India, even in SAC. ${ }^{6,7}$

The burden to individuals and communities from morbidity caused by STH has been extensively studied in India. Some studies have described the epidemiology of zoonotic helminths, primarily in dogs and pigs, but only a little data exist on the risks to humans from exposure to helminths in animal manure. ${ }^{8-14}$ However, the importance of these zoonotic helminths to human health has been highlighted recently with the detection of specific zoonotic helminths, e.g., the canine

*Address correspondence to Sitara Swarna Rao Ajjampur, Ida Scudder Road, Vellore, Tamil Nadu, India 632004. E-mail: sitararao@ cmcvellore.ac.in hookworm Ancylostoma ceylanicum in Australia and Southeast Asia and Ascaris suum, the roundworm of pigs, in Southeast Asia. ${ }^{15-18}$ A recent paper called for a greater inclusion of animals in WaSH methodologies, suggesting the inclusion of "Animal" as the " $A$ " in WaSH, would bring more focus to animals and their connection to water, sanitation, and hygiene. ${ }^{19}$ Exposure to animal feces has been proposed as an under-recognized threat to human health, ${ }^{20}$ and there is insufficient research on the role of domestic and wild animal feces in human disease. ${ }^{21,22}$

Targeted MDA appears unsuccessful at eliminating STH infection. Recent mathematical models, meta-analyses, and field trials suggest that high coverage of MDA delivered to all age groups could interrupt transmission. ${ }^{23-26}$ The DeWorm3 study is an international, ongoing series of cluster randomized trials in three sites, evaluating the feasibility of community-wide deworming to interrupt transmission of $\mathrm{STH}^{23}$ However, there are concerns that despite periodic community-wide MDA, potential zoonotic sources of helminth infection may undermine its efficacy by reinfection-either through direct contact or environmental contamination. ${ }^{27}$ This study uses data collected at the Jawadhu Hills sub-site of the DeWorm3 trial in India to estimate the prevalence of both helminth infections in domestic animals and helminth eggs in the environment. We use a "One Health" framework, considering the interconnectedness of human, animal, and environmental health to identify risks for exposure to helminth eggs.

\section{METHODS}

Study site. The Jawadhu Hills region, located in the Vellore and Thiruvanamalai districts in Tamil Nadu, India, is one of two Indian sub-sites for the Deworm3 trial. ${ }^{23}$ This hilly area has a 
population of approximately 60,000 people, mostly Malayali tribals living in villages and hamlets that are not easily accessible by road. ${ }^{28}$ Most of the population subsists on farming, and for parts of the year they work as migrant laborers in neighboring districts and states. ${ }^{6}$ Previous studies in this region have revealed high STH infection rates of $39 \% .{ }^{6}$ The study took place in a village of 104 households in which an annual census is performed as part of the Deworm 3 trial. ${ }^{23}$ This study was approved by the Christian Medical College IRB as an amendment to DeWorm3 (no. 10392) and by Tufts Health Science IRB (no. 13378). The head of the household gave informed consent for the livestock and environmental sampling, and the survey questionnaire.

\section{FIELD METHODS}

Survey. Every household in the village was eligible for inclusion in the survey, regardless of livestock ownership or household make-up. A survey was administered by trained field workers in Tamil to the head of the household to assess risk factors for exposure to helminth eggs, regarding contact with animal species, husbandry tasks, and high-risk behaviors around domestic animals, including the handling of manure or slaughtering of livestock. The survey was based on one previously used to record zoonotic risk factors. ${ }^{29}$ The head of the household was self-identified and could be any gender. To reduce survey burden on participants, information on additional WaSH practices such as latrine access and handwashing practices was extracted from the DeWorm3 annual census survey administered 8 months prior. ${ }^{23}$ Consumption of sick livestock was self-reported as part of a series of questions that asked what was done with sick livestock and whether the household would consume the animal, and which species. Each household also reported their most-used water source.

Sample collection. A single topsoil sample was collected from within 2 meters of the front door of each consenting study house using a $25-\mathrm{cm} \times 50-\mathrm{cm}$ stencil. With permission from village leaders, samples of soil were similarly collected from fecal fields (three each, with one from the center and two from access points) and one from within 2 meters of each village water source (pumps or wells). Fecal samples were collected from each domestic animal species owned by every study household and were obtained fresh after the animal was observed defecating. Feces was pooled from up to ten animals per species per household during sample collection (Figure 1). Samples were stored and transported on ice for fewer than 12 hours before being processed in the laboratory.
Microscopy and soil analysis. Pooled animal fecal samples were divided into three aliquots for microscopic examination, which was conducted on the same day. Three comparative methods were used: two aliquots of 5 grams each were used for the centrifugation and flotation methods, and 1 gram was used for Kato-Katz method, using duplicate slides. ${ }^{30-32}$ For all animal samples, a centrifugal flotation and sedimentation method was used to identify helminth eggs, according to standard operation procedures based on the Tropical Council for Companion Animal Parasites. ${ }^{33}$ Environmental soil samples were analyzed using a centrifugal flotation technique developed to standardize helminth egg collection from soil. ${ }^{34}$ Soil moisture was recorded by weighing out $30 \mathrm{~g}$ of soil and re-weighing after drying at $110^{\circ} \mathrm{C}$ for 12 hours. The $\mathrm{pH}$ and soil type were recorded for each sample.

Statistical methodology. The analysis examined the variable of exposure of contact with animals on the outcome of having helminth eggs in the household soil. Soil moisture was tested as a potential mediator, and WASH practices and socioeconomic factors were controlled as potential confounders.

The prevalence of helminths eggs in animal feces and in household soil samples were calculated by species. Socioeconomic status was determined from the DeWorm3 census, which ranks households according to quintiles based on factor analysis of the censused Jawadhu Hills study population. SES quintiles were treated as a categorical variable, as the relationship with the outcome was nonlinear. Household soil exposure, the primary outcome, was defined as having at least one helminth egg present in the household soil sample. Distance to water source was measured as straight-line distance in meters, and it was transformed using natural log for the regression analysis.

Descriptive statistics were calculated for characteristics of households and their surrounding environments. Prevalence estimates are presented with $95 \%$ binomial confidence intervals (Cls), and continuous variables are summarized using arithmetic means and SD. Further descriptive statistics were calculated for risk behaviors, stratified according to age and gender and then tested using $x^{2}$ tests. Univariable associations between contamination of the household environment and risk factors (household, animal, and environmental) were examined using logistic regression. Multivariable logistic regression was performed to build a model to examine the relationship of the principal exposure of interest of animal contact, accounting for additional related risk factors associated at the threshold of $P<0.10$. The final model was checked for collinearity using variance inflation factors, and continuous variables were tested for assumptions of linearity.
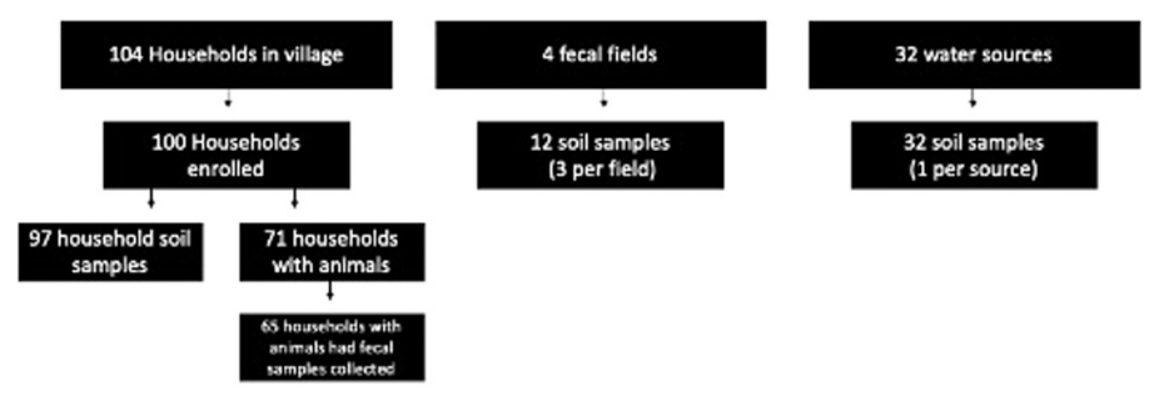

FIGURE 1. Samples by type and location. 
Soil moisture was tested as a potential mediator on the effect of animal contact on helminths in household soil using the approach established by Imai et al. (2010). ${ }^{35}$ All statistics were calculated using R Studio (v. 1.2.5042, R Core Team, Vienna, Austria) and mediation was tested using the $R$ package mediation (v. 4.5.0, Teppei Yamamoto).

\section{RESULTS}

Characteristics of study households and participants. Of the 104 households enumerated in the study village, 100 consented to participate (Figure 1). Four households were unavailable because of temporary migration. Of the 428 people across the 100 households, 218 were female and 210 were male; 52 (12.2\%) were 5 years old or younger, and 14 (3.3\%) were older than 64 . The average household size was 4.3 residents, and $41 \%$ of households had children under the age of 5 . Also, $77 \%$ of households reported access to water in their own yard/plot.

Households with domestic animals. A total of 71 households reported having contact with domestic animals. There were six main species, with cattle being most common ( $n=$ $68)$, followed by dogs $(n=46)$, chickens $(n=37)$, goats $(n=35)$, and pigs $(n=18)$. Fewer than three households each reported owning doves, sheep, parrots, water buffalo, or rabbits. Reported contact with domestic animals was similar for males and females, although significantly more females worked with chickens $(P=0.01$, Table 1$)$. Households participated in various husbandry tasks, the most common being the use of livestock for farm work or transportation $(n=23)$. Twelve households collected eggs from chickens, nine households milked their cows, and seventeen households reported slaughtering their own livestock. Slaughter, general care of livestock, care for sick/injured animals, and use of livestock for transportation of farm work was more commonly done by males, while handling of manure was more commonly done by females (Table 1). Handling manure was most commonly done by women older than 18 years old (>60\%).

Helminths in animals and soil locations. Animal fecal samples were collected from domestic animals from 65 of the 71 households reported as having contact with animals
(Figure 1). Samples could not be collected from six households because of the nonavailability of the animals, primarily because of recent deaths or slaughter. Samples were not obtained from some families running shared herds, particularly goats. Shared herds were marked with both household IDs.

Of all animal samples, $68 \%$ had helminth eggs ( $n=90 / 132$ ). High egg levels $(\geq 70 \%)$ were recorded in goats, dogs, and chickens (Table 2). The most common species in dogs were hookworms (73\%), with at least two dogs having mixed infections by egg size. Every pooled sample from goats (100\%) had strongyle-type eggs, which cannot be speciated visually. Chickens were primarily infected by a variety of avian tapeworms (37\%), Capillaria spp. (23\%), and Heterakis sp. (17\%). Helminth infections were found in animals associated with $86 \%(n=56)$ of sampled households. Of these, $47 \%(n=62)$ of samples had potentially zoonotic helminth eggs and $71 \%$ of households $(n=46)$ had at least one animal shedding potentially zoonotic eggs. (Only certain species of ruminant strongyle-type eggs are zoonotic, so cattle and goat strongyle-type eggs are labeled as only potentially zoonotic.)

Household soil was collected from 97 households (Figure 1). Three households had stone or concrete in front of their house, preventing collection. Mean moisture content was $1.3 \mathrm{~g}$ per $30 \mathrm{~g}$ of soil. Helminth eggs were found in $44 \%$ of household soil samples $(n=43 / 97)$. All three species of STH were found in the household soil, with Trichuris spp. (24.7\% of soil samples) being the most common, followed by hookworm (17.5\%), strongyle-type (10.3\%), and Strongyloides spp. (8.2\%). One soil sample each contained Toxocara spp. and Ascaris eggs. Greater than $75 \%$ of household soil samples had rhabditiform larva $(n=73 / 97)$.

Soil was collected at three locations (two access locations and midfield) within four different fecal fields (Figure 2). Mean moisture content was $0.2 \mathrm{~g}$ per $30 \mathrm{~g}$ of soil. Of the 12 samples, $67 \%$ had helminth eggs $(n=8)$, and each field had at least one positive soil sample. The most common helminth egg was hookworm egg (41.7\% of fecal soil samples), followed by Trichuris spp. (25\%), two samples with Strongyloides spp., and 1 sample with strongyle-type eggs. All twelve samples had rhabditiform larva (100\%). Water source soil (collected

TABLE 1

Contact with domestic animals and husbandry tasks by gender

\begin{tabular}{|c|c|c|c|}
\hline & Male $(\%)(n=210)$ & Female $(\%)(n=218)$ & $P$ value \\
\hline \multicolumn{4}{|l|}{ Species } \\
\hline Cattle & $103(49.0)$ & $91(41.7)$ & 0.14 \\
\hline Goats & $55(26.0)$ & $55(26.2)$ & 0.83 \\
\hline Pigs & $17(8.1)$ & 26 (11.9) & 0.20 \\
\hline Chickens & $32(15.2)$ & $55(25.2)$ & 0.01 \\
\hline Dogs & $64(30.5)$ & 75 (34.4) & 0.41 \\
\hline None & $63(30.0)$ & $71(32.5)$ & 0.60 \\
\hline \multicolumn{4}{|l|}{ Husbandry task } \\
\hline Milking & $6(2.9)$ & $8(3.7)$ & 0.79 \\
\hline Collecting eggs & $4(1.9)$ & $11(5.1)$ & 0.11 \\
\hline Slaughter & $16(7.6)$ & $3(1.4)$ & 0.002 \\
\hline Caring for young & $28(13.3)$ & $20(9.2)$ & 0.22 \\
\hline Caring for sick or injured & $31(14.8)$ & 18 (8.3) & 0.048 \\
\hline General care & $106(50.5)$ & $74(33.9)$ & 0.006 \\
\hline Transportation or farm work & 29 (13.8) & $3(1.4)$ & $<0.001$ \\
\hline Handling manure & 41 (19.5) & $93(42.7)$ & $<0.001$ \\
\hline Companionship/play & $27(12.9)$ & 25 (11.5) & 0.77 \\
\hline None & 73 (34.8) & $86(39.5)$ & 0.32 \\
\hline
\end{tabular}


TABLE 2

Helminth results from animal fecal samples by species

\begin{tabular}{|c|c|c|c|}
\hline Animal species $(n)$ & $\begin{array}{l}\text { Households with } \\
\text { animal contact }\end{array}$ & $\begin{array}{l}\text { Total of pooled samples with } \\
\text { helminth eggs }(n, \%)^{\star}\end{array}$ & Most common helminth species \\
\hline Cattle (44) & 68 & $22(50.0)$ & $\begin{array}{l}\text { Strongyle-type (45\%), Toxocara vitulorum } \\
(20 \%)\end{array}$ \\
\hline Goats (21) & 35 & 21 (100.0) & $\begin{array}{l}\text { Strongyle-type (100\%), Trichuris spp. } \\
(20 \%), \text { Strongyloides spp. (19\%) }\end{array}$ \\
\hline Chickens (30) & 37 & $21(70.0)$ & $\begin{array}{l}\text { Avian tapeworms (37\%), Capillaria spp. } \\
\text { (23\%), Strongyle-type (17\%) }\end{array}$ \\
\hline Dogs (15) & 46 & $13(86.7)$ & $\begin{array}{l}\text { Hookworm (73\%) (Ancylostoma caninum, } \\
\text { Ancylostoma ceylanicum), Toxocara } \\
\text { canis }(13 \%)\end{array}$ \\
\hline Pigs (15) & 18 & $8(53.3)$ & $\begin{array}{l}\text { Ascaris suum (40\%), Strongyle-type } \\
(13 \%)\end{array}$ \\
\hline
\end{tabular}

within $2 \mathrm{~m}$ of a water source, Figure 2) had the highest mean moisture content of the soil locations sampled $(2.1 \mathrm{~g}$ per $30 \mathrm{~g}$ of soil). Of the 32 samples collected from 32 water sources, $87.5 \%$ had helminth eggs $(n=28)$. The most common helminth egg was strongyle-type eggs ( $68.8 \%$ of water source soil samples), followed by Trichuris spp. (43.8\%), Strongyloides spp. (21.9\%), Toxocara spp. (9.3\%), and two samples with Ascaris spp. All three soil sample types could have multiple egg types per a single sample. Greater than $90 \%$ of soil samples taken near a water source had rhabditiform larva $(n=$ 30/32). Of all soil locations sampled, semi-quantitative analysis of egg counts per gram of soil identified the highest levels in water source soil.

Risk factors associated with exposure to contaminated household soil. Most households were in the third quintile ( $n=$ 30) of socioeconomic status (SES), and 17 households were in the poorest quintile (quintile 1). Households with and without helminth eggs in household soil had similar percentages of handwashing after touching manure and handling animal manure (Table 3). Median distance traveled to water was 32.0 meters, with $75 \%$ of households walking less than 80 meters (Figure 2B). Using a public water source was common in SES quintile $1-4$, occurring in $17.6 \%$ of quintile $1(n=3), 31.8 \%$ of quintile $2(n=7), 26.7 \%$ of quintile $3(n=8), 20.0 \%$ of quintile 4 $(n=4)$, and $0.0 \%$ of quintile $5(n=0)$.

Univariable analysis by WaSH risk factors and animal contact resulted in identification of four variables significantly associated with the odds of helminth eggs in household soil: contact with domestic animals, consumption of sick livestock, water source at the household, and soil water weight (Table 3). Soil moisture had a linear association with contaminated household soil. Contact with domestic animals, consumption of sick livestock, and increased soil water weight were all associated with an increased risk for helminth eggs in the household soil. Having a water source at the household, e.g., a pump, rather than going to a community pump or well, reduced the risk of helminth eggs in the household soil. In the final model, contact with domestic animals $(\mathrm{OR}=4.1, \mathrm{Cl}$ : 1.45-12.87) and consumption of sick livestock (OR $=2.4, \mathrm{Cl}$ : 0.96-6.13) were significantly positively associated. Water at the household $(\mathrm{OR}=0.33, \mathrm{Cl}$ : $0.11-0.92)$ was negatively associated with exposure to helminth eggs in the household soil. All variance inflation factors were below 1.1; the collinearity between the exposure variables was at an acceptable level.
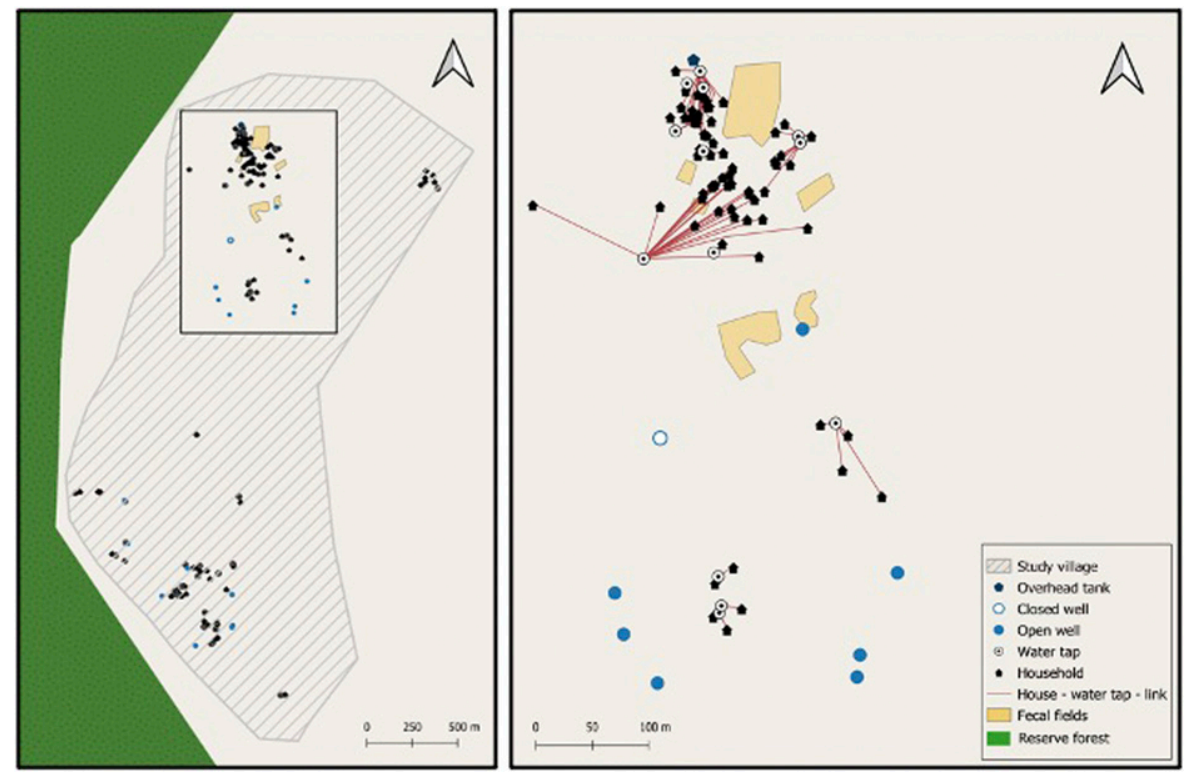

FIGURE 2. (A) Map showing the entire extant of the study village. (B) Box inset showing relationship between households and reported household water sources. This figure appears in color at www.ajtmh.org. 
TABLE 3

Univariate and multivariable analysis of household characteristics for exposure to helminth eggs in household soil

\begin{tabular}{|c|c|c|c|c|c|c|}
\hline \multirow[b]{2}{*}{ Household characteristics } & \multirow[b]{2}{*}{$\begin{array}{l}\text { Households with } \\
\text { risk factor }(n=97)\end{array}$} & \multirow[b]{2}{*}{$\begin{array}{l}\text { Helminth eggs present } \\
\text { in soil }(n=43)\end{array}$} & \multicolumn{2}{|l|}{ Univariate } & \multicolumn{2}{|l|}{ Multivariable ${ }^{\star}$} \\
\hline & & & $\mathrm{OR}(95 \% \mathrm{Cl})$ & $P$ value & OR $(95 \% \mathrm{Cl})$ & $P$ value \\
\hline Contact with domestic animals $(n, \%)$ & $70(72.2)$ & $37(86.0)$ & $3.92(1.48-11.77)$ & $0.01^{*}$ & $4.05(1.45-12.87)$ & $0.01^{*}$ \\
\hline Task: Handle manure $(n, \%)$ & $68(70.1)$ & $31(72.1)$ & $1.19(0.50-2.91)$ & 0.70 & & \\
\hline Consumption of sick livestock ( $n, \%)$ & $32(32.3)$ & $19(44.2)$ & $2.50(1.10-6.10)$ & $0.04^{*}$ & $2.39(0.96-6.13)$ & 0.06 \\
\hline Hand washing after touching manure $(n, \%)$ & $91(93.8)$ & $41(95.3)$ & $1.64(0.30-12.26)$ & 0.57 & & \\
\hline Water on property $(n, \%)$ & 75 (77.3) & $29(67.4)$ & $0.36(0.13-0.95)$ & $0.04^{*}$ & $0.33(0.11-0.92)$ & $0.04^{*}$ \\
\hline $\begin{array}{l}\text { Distance to water source in meters } \\
\text { (median, IQR) } \dagger\end{array}$ & 31.7 (53.0) & 37.04 (75.3) & $1.34(0.90-2.05)$ & 0.16 & & \\
\hline Children $\leq 5$ years $(n, \%)$ & $29(29.9)$ & $15(34.9)$ & $0.67(0.29-1.52)$ & 0.34 & & \\
\hline Use of open well, lake, or pond ( $n, \%)$ & $86(88.7)$ & $36(83.7)$ & $2.43(0.68-9.86)$ & 0.18 & & \\
\hline Socioeconomic status: Quintile 1 (low) & $17(17.5)$ & $8(18.6)$ & & & & \\
\hline Quintile 2 & $22(22.7)$ & $10(23.3)$ & $0.93(0.26-3.37)$ & 0.92 & & \\
\hline Quintile 3 & $30(30.9)$ & $9(20.9)$ & $0.48(0.14-1.65)$ & 0.25 & & \\
\hline Quintile 4 & $20(20.6)$ & $12(27.9)$ & $1.69(0.46-6.42)$ & 0.43 & & \\
\hline Quintile 5 (high) & $8(8.2)$ & $4(9.3)$ & $1.13(0.20-6.28)$ & 0.89 & & \\
\hline $\begin{array}{l}\text { House-type (Kutcha: mud/thatch vs. all } \\
\text { others) }\end{array}$ & $55(56.7)$ & $23(53.5)$ & $0.73(0.32-1.65)$ & 0.45 & & \\
\hline $\begin{array}{l}\text { Number of domestic animal species in the } \\
\text { household (mean, SD) }\end{array}$ & $1.3(1.3)$ & $1.4(1.2)$ & $1.13(0.82-1.55)$ & 0.45 & & \\
\hline $\begin{array}{l}\text { Number of household members (mean, } \\
\text { SD) }\end{array}$ & $4.4(1.8)$ & $4.2(1.7)$ & $0.92(0.73-1.15)$ & 0.47 & & \\
\hline Soil moisture content in grams (mean, SD) & $1.16(1.15)$ & $1.63(1.3)$ & $2.07(1.39-3.26)$ & $0.001 t$ & & \\
\hline
\end{tabular}

${ }^{*}$ For variables that met the inclusion criteria of $P<0.1$ in the final multivariable model, excluding soil moisture as a potential mediato $\dagger$ Distance to water source in meters was log transformed for the univariable analysis.

Three species of sick livestock were reported as being eaten; chickens were most common $(n=29)$, then goats $(n=19)$, and two households reported eating sick swine.

Mediation analysis for soil moisture. Soil moisture was analyzed as a potential mediator for the effect of contact with domestic animals with the outcome of helminth eggs in household soil. The total effect of animal contact on helminth eggs in the household soil was significant $(P=0.02)$, but the direct effect-after taking into account the mediation effect of soil moisture-was not significant $(P=0.2)$. Soil moisture was a mediator with a significant indirect effect $(P<0.001)$; the proportion mediated was 0.50 (Cl: 0.087-1.97).

\section{DISCUSSION}

Our study uses a One Health framework to examine potential risk factors for and exposure to environmental helminth eggs, including potential zoonotic helminth eggs. Focusing only on helminth infection in humans may miss key opportunities to prevent infection and may overlook the role of the environment and animals.

Contact with animals was reported by almost $70 \%$ of the households in this study, with almost half of the households owning dogs. Our study found that $73 \%$ of dogs shed hookworms, which is in line with other reports from India and Southeast Asia, which range from 45-90\%.8,9,36 In India and Southeast Asia, the primary species of canine hookworm are $A$. caninum and $A$. ceylanicum, ${ }^{8,9,36}$ though we did not speciate the canine hookworm in this study. Previous work in this region had revealed a high hookworm infection rate in community members ${ }^{6}$; PCR of 119 samples from that cohort identified $17 \%$ as $A$. caninum, a zoonotic hookworm from dogs. $^{27}$ Studies from South Africa have also identified A. caninum eggs in human stool, and a juvenile female A. caninum was recovered from a colonoscopy in South Korea. ${ }^{27,37,38} A$. ceylanicum, another canine zoonotic hookworm, is known to cause patent infections in humans; and more recent molecular studies have shown it to be more prevalent than initially reported. ${ }^{9,17,18,39}$ The potential for reinfection in humans following MDA by $A$. ceylanicum was identified in Laos. ${ }^{39}$ This hookworm has also been found in children in Tamil Nadu. ${ }^{16}$

Embryonated STH eggs in the soil become ingested either through contamination of food or poor hygiene practices via the fecal-oral route. ${ }^{40}$ The presence of helminth eggs in household soil has been previously used to quantify human exposure to helminth eggs. Soil helminths have been used as the outcome measure to determine if a WaSH sanitation intervention reduced potential exposure to helminth eggs in the environment. ${ }^{41}$ Environmental prevalence of hookworm eggs when measured by microscopy was shown to be within $5 \%$ of helminth egg prevalence in humans. ${ }^{27}$ Furthermore, household soil prevalence in that study was correlated to a higher degree with human infection rates than with canine rates. ${ }^{27}$ All three species of STH were found in household soil, as well as helminth eggs, suggestive of contamination with animal and zoonotic helminths. The high level of Trichuris spp. implies contamination with ruminant feces, as previous work recorded a low level of human infections by Trichuris spp. ${ }^{6}$ Hookworm was the most common STH in fecal field soil and second most common in household soil, which reflects previous studies identifying hookworm as the most common human helminth in this area. ${ }^{27}$ Potentially zoonotic hookworm eggs were also shed by greater than $70 \%$ of sampled dogs. This rate suggests that household soil was reflective of both human and domestic animal infections, suggesting a potential route for the spread of zoonotic canine hookworms.

WaSH risk factors, such as use of open source water, were practiced by the majority of households and were not associated with helminth eggs in the soil. While contact with domestic animals has been reported as a known association with helminth infections, ${ }^{42,43}$ our study also identified an 
association between consumption of sick livestock and helminths. It is unknown if this is a risk factor inherent in the activity of consuming ill livestock, or if it is a proxy for food insecurity or other unmeasured factors, such as slaughter practices; however, adding SES did not affect the significance of the result. Consumption of sick livestock by households has been reported in Southeast Asia. ${ }^{44}$

Water collection from a public source (away from the household) was also identified as a risk factor for exposure to helminth eggs and remained significant after accounting for SES. More than $15 \%$ of households in SES quintile 1-4 collected water from a public source. Distance to a water source, however, was not significant $(P=0.16)$; though the median distance traveled for households with helminth eggs in household soil was longer. Water source soil had the highest egg count of any soil type, and almost $90 \%$ of those samples had helminth eggs. Water sources (both public and within the household compounds) included pumps, and open and closed wells. However, many of the pumps were observed to have standing water from runoff that animals used for drinking or wallowing in, immediately adjacent to the pump. This activity represents a potential source of contamination of household soil, as people or animals may be tracking eggs back from a water source. Water source soil was distinct from household soil, because even when the water source was within the household compound, the shortest distance between the water source and the front door was more than 4 meters.

Soil moisture has been previously associated with increased presence of helminth eggs in soil. ${ }^{41}$ Field and laboratory studies have found that increased humidity and soil moisture increased egg development and survival of larva. ${ }^{45}$ In our risk factor analysis, soil moisture was considered a potential mediator, rather than a confounder, because of contact with soil moisture most likely occurring temporally after the exposure variable of the household having contact with animals. Soil moisture mediated half of the effect associated with contact with domestic animals. The direct effect of animal contact, after accounting for the mediator, was no longer significant; but this result is potentially because of the small sample size. As soil moisture is known to support helminth egg development, drainage and keeping the soil in front of the household dry may be an intervention to consider in future studies in areas with domestic animals, especially livestock.

In addition to concerns related to human health and environmental contamination, many of these helminths also cause morbidity and mortality in livestock and dogs, especially in young animals. ${ }^{46}$ In our study, every pooled sample from goats had helminth eggs, and villagers reported death of kids (baby goats) with signs suggestive of helminth infections. Goats are a significant source of meat and revenue for villagers. Zoonotic helminths can thus affect food security as well as impact human and animal health.

An important strength of this study was the use of a One Health framework to look at human risk factors alongside animal health and environmental variables. All occupied households in the village completed surveys. This strategy allowed for a more complete picture to be formed about the risks for human exposure to STHs.

There were some limitations inherit to the study designs. This was a cross-sectional study, so only associations and not causative relationships can be recorded. We examined exposure but not transmission. Human fecal samples could not be included because of the need to preserve blinding within the ongoing DeWorm3 trial. Human samples have been collected and banked from this village for testing after conclusion of the trial. Furthermore, as this was a small sample of a single village, there are limits to generalizability, because agricultural and cultural practices are likely different in different parts of India. Other limits to generalizability are the wide range of environmental and geographic heterogeneity across India and how this effects STHs. However, the methodology and the survey used have potential to be employed across a variety of settings. Sample size also likely limited significance for certain risk factors, including husbandry tasks, such as home slaughter of livestock. Molecular methods were not used to identify the species of helminth egg identified by microscopy. Finally, this study did not investigate seasonal effects. Livestock helminth infections tend to be at the lowest during the dry season, when this study occurred. ${ }^{47}$ Canine hookworm, conversely, has been found in Gujarat, India to be highest in May, right before the monsoon season. ${ }^{48}$ This would suggest that canine hookworm was at a high point and ruminant helminths at a low point across seasonal cycles when this study occurred.

\section{CONCLUSIONS}

This study used a One Health framework to examine the association between contact with domestic animals and the potential effects that animal fecal matter may have on human health. High levels of helminth infections were found across domestic animal species, especially in goats, chickens, and dogs. Dogs are carriers of zoonotic hookworms, which are a significant health concern and a potential target for intervention at the household level. The three factors associated with exposure to helminth eggs in household soil were contact with animals, retrieving water away from the household, and consumption of sick livestock. Soil moisture was found to be a mediator, accounting for $50 \%$ of the association between contact with livestock and exposure to helminth eggs in household soil. This study provides a foundation for further investigation of the consequences of animals and animal fecal matter on human health, as well as identifying potential exposure routes for STH and zoonotic helminths.

Received November 16, 2020. Accepted for publication February 11, 2021.

Published online May 24, 2021.

Acknowledgments: We would like to thank the DeWorm3 field, data, and lab teams, who supported sample and data collection at Christian Medical College, Vellore, including Joel Thamburaj, Janarthanan Maniyarasu, Naveenkumar Sekar, and Venkateshprabhu Janagaraj. We thank the families in Jawadhu Hills who consented to participate in this study. We thank Anne V. Kane, MD, Tufts Medical Center, for critical reading and editing of the manuscript.

Financial support: The project was supported by a TL1 grant to A. S. from the National Center for Advancing Translational Sciences, National Institutes of Health, Award Number UL1TR002544. The content is solely our responsibility and does not necessarily represent the official views of the $\mathrm{NIH}$. The project was also supported by a Fellowship Grant from the Tufts' Institute of the Environment to A. S. The DeWorm3 study is funded through a grant to the Natural History Museum, London from the Bill and Melinda Gates Foundation (OPP1129535, PI JLW). 
Authors' addresses: Alexandra Sack, Tufts Clinical and Translational Science Institute, Tufts Graduate School of Biomedical Sciences, Boston, MA, E-mail: alexandra.sack@tufts.edu. Gokila Palanisamy, Malathi Manuel, Chinnaduraipandi Paulsamy, Saravanakumar Puthupalayam Kaliappan, and Sitara Swarna Rao Ajjampur, The Wellcome Trust Research Laboratory, Division of Gastrointestinal Sciences, Christian Medical College, Vellore, Tamil Nadu, India, E-mails: gokilap01896@gmail.com, malathimanuel25@gmail.com, chechinnadurai@gmail.com, epipks@gmail.com, and sitararao@ cmcvellore.ac.in. Anuradha Rose, Department of Community Medicine, Christian Medical College, Vellore, Tamil Nadu, India, E-mail: anurose@cmcvellore.ac.in. Honorine Ward, Division of Geographic Medicine and Infectious Diseases, Tufts Medical Center, Tufts University School of Medicine, Boston, MA, E-mail: hward@ tuftsmedicalcenter.org. Judd L. Walson, Departments of Global Health, Medicine (Infectious Disease), Pediatrics and Epidemiology, University of Washington, Seattle, WA, E-mail: walson@uw.edu. Katherine E. Halliday, Faculty of Infectious and Tropical Diseases, London School of Hygiene \& Tropical Medicine, London, United Kingdom, E-mail: katherine.halliday@Ishtm.ac.uk.

\section{REFERENCES}

1. Lai $Y$-S, Biedermann $P$, Shrestha $A$, Chammartin $F$, à Porta $N$, Montresor A, Mistry NF, Utzinger J, Vounatsou P, 2019. Risk profiling of soil-transmitted helminth infection and estimated number of infected people in South Asia: a systematic review and Bayesian geostatistical analysis. PLoS Negl Trop Dis 13: e0007580.

2. Jourdan PM, Lamberton PHL, Fenwick A, Addiss DG, 2018. Soiltransmitted helminth infections. Lancet 391: 252-265.

3. Strunz EC, Addiss DG, Stocks ME, Ogden S, Utzinger J, Freeman MC, 2014. Water, sanitation, hygiene, and soil-transmitted helminth infection: a systematic review and meta-analysis. PLoS Med 11: e1001620.

4. World Health Organization, 2017. Guideline: Preventive Chemotherapy to Control Soil-transmitted Helminth Infections in Atrisk Population Groups. Geneva, Switzerland: WHO.

5. Press Information Bureau Government of India, 2019. Health Ministry Conducts 8th Round of National Deworming Day (NDD) Campaign. Available at: https://pib.gov.in/Pressreleaseshare. aspx?PRID=1563589. Accessed March 28, 2021.

6. Kaliappan SP et al., 2013. Prevalence and clustering of soiltransmitted helminth infections in a tribal area in southern India. Trop Med Int Health 18: 1452-1462.

7. Ganguly $S$ et al., 2017. High prevalence of soil-transmitted helminth infections among primary school children, Uttar Pradesh, India, 2015. Infect Dis Poverty 6: 139.

8. Traub RJ, Robertson ID, Irwin P, Mencke N, Thompson RCA, 2002. The role of dogs in transmission of gastrointestinal parasites in a remote tea-growing community in northeastern India. Am J Trop Med Hyg 67: 539-545.

9. Traub RJ, Robertson ID, Irwin P, Mencke N, Monis $P$, Thompson RCA, 2003. Humans, dogs and parasitic zoonoses-unravelling the relationships in a remote endemic community in northeast India using molecular tools. Parasitol Res 90: S156-S157.

10. Panigrahi PN, Gupta AR, Behera SK, Panda BSK, Patra RC, Mohanty BN, Sahoo GR, 2014. Evaluation of gastrointestinal helminths in canine population of Bhubaneswar, Odisha, India: a public health appraisal. Vet World 7: 295.

11. Traub RJ, Robertson ID, Irwin PJ, Mencke N, Thompson RCAA, 2005. Canine gastrointestinal parasitic zoonoses in India. Trends Parasitol 21: 42-48.

12. Biswal DK, Debnath M, Kharumnuid G, Thongnibah W, Tandon V, 2016. Northeast India Helminth Parasite Information Database (NEIHPID): knowledge base for helminth parasites. PLoS One 11: e0157459.

13. Borkataki S, Islam S, Borkakati MR, Goswami P, Deka DK, 2012. Prevalence of porcine cysticercosis in Nagaon, Morigaon and Karbianglong district of Assam, India. Vet World 5: 86.

14. Kaur M, Singh BB, Sharma R, Gill JPS, 2016. Pervasive environmental contamination with human feces results in high prevalence of zoonotic Sarcocystis infection in pigs in the Punjab, India. J Parasitol 102: 229-232.
15. Sadaow $L$ et al., 2018. Molecular identification of Ascaris lumbricoides and Ascaris suum recovered from humans and pigs in Thailand, Lao PDR, and Myanmar. Parasitol Res 117: 2427-2436.

16. George S, Kaliappan SP, Kattula D, Roy S, Geldhof P, Kang G, Vercruysse J, Levecke B, 2015. Identification of Ancylostoma ceylanicum in children from a tribal community in Tamil Nadu, India using a semi-nested PCR-RFLP tool. Trans $R$ Soc Trop Med Hyg 109: 283-285.

17. Inpankaew T et al., 2014. High prevalence of Ancylostoma ceylanicum hookworm infections in humans, Cambodia, 2012. Emerg Infect Dis 20: 976-982.

18. Ngui R, Lim YAL, Traub R, Mahmud R, Mistam MS, 2012. Epidemiological and genetic data supporting the transmission of Ancylostoma ceylanicum among human and domestic animals. PLoS Negl Trop Dis 6: e1522.

19. Prendergast AJ et al., 2019. Putting the "A" into WaSH: a call for integrated management of water, animals, sanitation, and hygiene. Lancet Planet Health 3: e336-e337.

20. Berendes DM, Yang PJ, Lai A, Hu D, Brown J, 2018. Estimation of global recoverable human and animal faecal biomass. Nat Sustain 1: 679-685.

21. Matilla F, Velleman Y, Harrison W, Nevel M, 2018. Animal influence on water, sanitation and hygiene measures for zoonosis control at the household level: a systematic literature review. PLoS Negl Trop Dis 12: e0006619.

22. Penakalapati G, Swarthout J, Delahoy MJ, McAliley L, Wodnik B, Levy K, Freeman MC, 2017. Exposure to animal feces and human health: a systematic review and proposed research priorities. Environ Sci Technol 51: 11537-11552.

23. Asbjornsdottir $\mathrm{KH}$ et al., 2018. Assessing the feasibility of interrupting the transmission of soil-transmitted helminths through mass drug administration: the DeWorm3 cluster randomized trial protocol. PLoS Negl Trop Dis 12: e0006166.

24. Clarke NE, Clements ACA, Doi SA, Wang D, Campbell SJ, Gray D, Nery SV, 2017. Differential effect of mass deworming and targeted deworming for soil-transmitted helminth control in children: a systematic review and meta-analysis. Lancet 389: 287-297.

25. Clarke NE, Clements ACA, Bryan S, McGown J, Gray D, Nery SV, 2016. Investigating the differential impact of school and community-based integrated control programmes for soiltransmitted helminths in Timor-Leste: the (S)WASH-D for Worms pilot study protocol. Pilot Feasibility Stud 2: 69.

26. Coffeng LE et al., 2019. Impact of different sampling schemes for decision making in soil-transmitted Helminthiasis control programs. J Infect Dis 221 (Supp 5): S531-S538.

27. George S, Levecke B, Kattula D, Velusamy V, Roy S, Geldhof P, Sarkar R, Kang G, 2016. Molecular identification of hookworm isolates in humans, dogs and soil in a tribal area in Tamil Nadu, India. PLoS Negl Trop Dis 10: e0004891.

28. Office of the Registrar General \& Census Commissioner, 2011. C.D. Block Wise Primary Census Abstract Data (PCA). Tamil Nadu, India: author.

29. Sack A, Daramragchaa U, Chuluunbaatar M, Gonchigoo B, Gray $\mathrm{GC}, 2018$. Potential risk factors for zoonotic disease transmission among Mongolian herder households caring for horses and camels. Pastoralism 8: 2.

30. Utzinger J, Becker SL, van Lieshout L, van Dam GJ, Knopp S, 2015. New diagnostic tools in schistosomiasis. Clin Microbiol Infect 21: 529-542.

31. Levecke B et al., 2011. A comparison of the sensitivity and fecal egg counts of the McMaster egg counting and Kato-Katz thick smear methods for soil-transmitted helminths (diagnostic methods for soil-transmitted helminths). PLoS Negl Trop Dis 5: e1201.

32. Speich B, Knopp S, Mohammed KA, Khamis IS, Rinaldi L, Cringoli G, Rollinson D, Utzinger J, 2010. Comparative cost assessment of the Kato-Katz and FLOTAC techniques for soil-transmitted helminth diagnosis in epidemiological surveys. Parasit Vectors 3: 71.

33. Tropical Council for Companion Animal Parasites, 2019. Guidelines for the diagnosis, treatment and control of canine endoparasites in the tropics. Available at: https://www.troccap.com/ canine-guidelines/. Accessed June 1, 2019. 
34. Steinbaum L, Kwong LH, Ercumen A, Negash MS, Lovely AJ, Njenga SM, Boehm AB, Pickering AJ, Nelson KL, 2017. Detecting and enumerating soil-transmitted helminth eggs in soil: new method development and results from field testing in Kenya and Bangladesh. PLoS Negl Trop Dis 11: e0005522.

35. Imai K, Keele L, Tingley D, 2010. A general approach to causal mediation analysis. Psychol Methods 15: 309-334.

36. Tun S, Ithoi I, Mahmud R, Samsudin NI, Kek Heng C, Ling LY, 2015. Detection of helminth eggs and identification of hookworm species in stray cats, dogs and soil from Klang Valley, Malaysia. PLoS One 10: e0142231.

37. Jung B-K, Lee J-Y, Chang T, Song H, Chai J-Y, 2020. Rare case of nteric Ancylostoma caninum hookworm infection, South Korea. Emerg Infect Dis 26: 181.

38. Ngcamphalala PI, Lamb J, Mukaratirwa S, 2019. Molecular identification of hookworm isolates from stray dogs, humans and selected wildlife from South Africa. $J$ Helminthol 94: e39.

39. Conlan JV, Khamlome B, Vongxay K, Elliot A, Pallant L, Sripa B, Blacksell SD, FenwickS, Thompson RCA, 2012. Soil-transmitted helminthiasis in Laos: a community-wide cross-sectional study of humans and dogs in a mass drug administration environment. Am J Trop Med Hyg 86: 624.

40. Steinbaum L, Njenga SM, Kihara J, Boehm AB, Davis J, Null C, Pickering AJ, 2016. Soil-transmitted helminth eggs are present in soil at multiple locations within households in rural Kenya. PLoS One 11: e0157780.
41. Steinbaum L, Mboya J, Mahoney R, Njenga SM, Null C, Pickering AJ, 2019. Effect of a sanitation intervention on soil-transmitted helminth prevalence and concentration in household soil: a cluster-randomized controlled trial and risk factor analysis. PLoS Negl Trop Dis 13: e0007180.

42. Ekong PS, Juryit R, Dika NM, Nguku P, Musenero M, 2012. Prevalence and risk factors for zoonotic helminth infection among humans and animals-Jos, Nigeria, 2005-2009. Pan Afr Med J 12: 6.

43. Robinson MW, Dalton JP, 2009. Zoonotic helminth infections with particular emphasis on fasciolosis and other trematodiases. Philos Trans R Soc Lond B Biol Sci 364: 2763-2776.

44. Osbjer K, Boqvist S, Sokerya S, Kannarath C, San S, Davun H, Magnusson U, 2015. Household practices related to disease transmission between animals and humans in rural Cambodia. BMC Public Health 15: 476.

45. Brooker S, Clements ACA, Bundy DAP, 2006. Global epidemiology, ecology and control of soil-transmitted helminth infections. Adv Parasitol 62: 221-261.

46. Zajac A, 2012. Veterinary Clinical Parasitology. Chichester, West Sussex, United Kingdom: Wiley-Blackwell.

47. Velusamy R, Rani N, Ponnudurai G, Anbarasi P, 2015. Prevalence of intestinal and haemoprotozoan parasites of small ruminants in Tamil Nadu, India. Vet World 8: 1205.

48. Brahmbhatt NN, Patel PV, Hasnani JJ, Pandya SS, Joshi BP, 2015. Study on prevalence of ancylostomosis in dogs at Anand district, Gujarat, India. Vet World 8: 1405-1409. 